\title{
Poor care leads to 24000 premature deaths from diabetes in England each year
}

The title of this news article by Susan Mayor was misleading (BMJ 2011;343:d8081, doi:10.1136/bmj.d8081). It should have more accurately said: "Poor care contributes to some 24000 premature deaths from diabetes, new audit claims." Additionally, quoting Dr Bob Young, the story stated: "He said that this [the higher impact of mortality in people of working age] may relate to previous findings from the diabetes audit showing that young people with diabetes are more likely than older people to receive all components of recommended diabetes care." It should have said that young people with diabetes were less likely than older people to receive all components of recommended diabetes care.

Cite this as: BMJ 2011;343:d8288

๑ BMJ Publishing Group Ltd 2011 